\title{
ESTÁGIO CURRICULAR SUPERVISIONADO SOB A ÓPTICA DOS ENFERMEIROS SUPERVISORES
}

\section{SUPERVISED INTERSHIP UNDER THE NURSES' OPTICAL SUPERVISORY \\ PRÁCTICA PRE PROFESIONAL CURRICULAR SUPERVISADA BAJO LA ÓPTICA DE LOS SUPERVISORES ENFERMEROS}

\author{
Delvane José de Souza ${ }^{1}$, Maíla Fidalgo de Faria ${ }^{2}$, Ricardo Jader Cardoso ${ }^{3}$, Divanice Contim ${ }^{4}$
}

\begin{abstract}
Resumo
Objetivos: identificar a opinião dos enfermeiros supervisores do estágio hospitalar sobre fatores que dificultam sua atuação durante a supervisão; identificar a importância do estágio supervisionado para os enfermeiros e verificar a percepção destes quanto à sua participação durante o estágio curricular supervisionado hospitalar. Método: estudo exploratório descritivo com abordagem qualitativa, realizado em um hospital de ensino de uma cidade do Triângulo Mineiro. Foram entrevistados 45 enfermeiros que já atuaram como supervisores de estágio por meio de entrevista semiestruturada seguido de Análise de Conteúdo. Resultados: surgiram sete categorias: preparo profissional; importância do estágio curricular supervisionado; dificuldades presentes do estágio curricular supervisionado; despreparo dos acadêmicos; atribuições do enfermeiro; sugestões de melhoria para o estágio curricular supervisionado e responsabilidade de supervisionar. Conclusão: o estágio supervisionado é fundamental para a formação acadêmica, porém o desconhecimento de alguns enfermeiros sobre o papel de supervisor, o despreparo dos acadêmicos e falta de tempo dificultam a supervisão.
\end{abstract}

Palavras chave: Estágios, Programas de Graduação em Enfermagem, Pesquisa em Educação de Enfermagem.

\begin{abstract}
Objective: The main objective was to identify the opinion of supervisors of hospital internship about factors that may hamper their performance during supervision, identify what is the importance of the supervised intership for the nurses and verify their perception about their participation during the supervised hospital intership discipline.Method: a discriptive exploratory study with a qualitative approach, performed in a teaching hospital in a city located in Triângulo Mineiro, State of Minas Gerais, Brazil. 45 nurses that have worked as intership supervisors were interviewed through semi structured interviews followed by content analyses. Results: seven categories emerged: profesional preparation, the importance of the intership program, difficulties present in the intership program, unpreparedness of
\end{abstract}

\footnotetext{
${ }^{1}$ Enfermeiro. Doutor em Ciências. Centro de Graduação em Enfermagem. Universidade Federal do Triângulo Mineiro. UFTM. E-mail: delvane.jose@gmail.com

2 Enfermeira graduada na Universidade Federal do Triângulo Mineiro, (UFTM). E-mail: mailafidalgofaria@gmail.com

${ }^{3}$ Enfermeiro. Doutor em Enfermagem. Professor Associando do Centro de Graduação em Enfermagem da Universidade Federal do Triângulo Mineiro. UFTM. E-mail: jader10@uol.com.br

${ }^{4}$ Enfermeira. Doutor em Ciências. Professor Adjunto do Centro de Graduação em Enfermagem da Universidade Federal do Triângulo Mineiro. UFTM. E-mail: dcotim@uol.com.br
} 
academics, assignments of nurses, suggestions for improvement for the intership program and responsibility of supervising. Conclusion: supervised internship is essential for academic formation, however there is a lack of information by some of the nurses about their function as supervisor, the lack of preparation of the students and the lack of time make supervision difficult.

Key words: internship programs, graduation programs in Nursing, research in Nursing Education.

\section{Resumen}

Objetivos: identificar la opinión de los supervisores enfermeros de la práctica pre profesional hospitalaria acerca de los factores que dificultan su actuación durante la supervisión; identificar cual es la importancia de la práctica supervisada para los enfermeros y verificar su percepción en relación a su participación durante la disciplina de práctica pre profesional curricular hospitalaria supervisada. Método: estudio exploratorio descriptivo con abordaje cualitativa, realizado en un hospital de enseño de una ciudad del Triángulo Minero. Fueron entrevistados 45 enfermeros que ya actuaron como supervisores de prácticas pre profesional por medio de entrevista semi estructurada seguido de Análisis de Contenido. Resultados: surgieron siete categorías: preparo profesional, importancia de las prácticas pre profesionales, dificultades presientes en las prácticas pre profesionales, falta de preparación académica, atribuciones de lo enfermero, sugerencias de mejoría para las prácticas pré profesionales y responsabilidad de supervisión. Conclusión: la práctica pre profesional supervisada es fundamental para la formación académica, pero existe un desconocimiento de algunos enfermeros sobre el papel del supervisor, la falta de preparación académica y la falta de tiempo dificultan la supervisión.

Palabras clave: Pasantías, Programas de Graduación en Enfermería, Investigación en Educación de Enfermería.

\section{Introdução}

As Diretrizes Curriculares

Nacionais para enfermagem, homologadas em novembro de 2001, estabelecem os princípios, condições e procedimentos fundamentais para a formação dos enfermeiros, norteando as instituições de ensino superior a elaborarem currículos que possibilitem a formação de profissionais qualificados que prestem assistência integral à saúde. Desta forma, o Projeto Pedagógico do Curso de Enfermagem deve propor atividades extracurriculares, permitindo a vivência do ensino de forma teórica e prática. ${ }^{1}$
O estágio curricular supervisionado (ECS) é uma disciplina que permite a consolidação da teoria fornecida na graduação por meio de vivências práticas. Porém, apesar de sua reconhecida importância, muitos enfermeiros sentem dificuldades em desenvolver o papel de supervisor devido ao desconhecimento da metodologia a ser seguida no estágio, à interação falha entre supervisor-docentesacadêmicos e do sentimento de estar exercendo uma atividade que foge às suas competências de enfermeiro, comprometendo a qualidade da disciplina e da formação do acadêmico. ${ }^{2}$ 
Dentre as diversas legislações que regulamentam a realização do ECS, a Legislação Federal 11788 de 25 de setembro de 2008 é a que estabelece a carga horária de trinta horas semanais para a realização do estágio, sendo permitindo um estagiário para até cinco trabalhadores e dois estagiários para seis a dez trabalhadores, sendo obrigatória a atuação de um docente da instituição de ensino em conjunto com um profissional do local onde será desenvolvido o estágio. ${ }^{3}$

O estágio supervisionado visa possibilitar que o acadêmico tenha vivências da profissão, relacione teoria e prática; estabeleça vínculo entre a academia e a sociedade, aperfeiçoe suas habilidades técnico-científicas, seja estimulado a exercer a assistência integral e multidisciplinar, além de vivenciar e refletir acerca dos aspectos éticos e legais inerentes à profissão. ${ }^{4}$

Para que os objetivos do ECS sejam alcançados, é fundamental a integração entre docente-enfermeiro-acadêmico. $\mathrm{O}$ enfermeiro do campo de estágio é a referência para o acadêmico que observa suas atitudes e posturas, refletindo e relacionando o conhecimento teórico às situações vivenciadas. Quando há uma boa relação entre as partes há um enriquecimento mútuo por meio da troca de conhecimentos práticos e informações atualizadas, inovando o espaço dos serviços de saúde. ${ }^{5}$

O serviço de saúde utilizado como campo de estágio também é parte fundamental para a graduação em enfermagem, pois fornece uma ampla oportunidade de ensino, possibilitando que o acadêmico vivencie o cuidado em todos os seus aspectos, reflita sobre a realidade do ambiente de trabalho e contribua para a melhoria do mesmo por meio do conhecimento científico em que a enfermagem é fundamentada. ${ }^{6}$

Acreditamos que a supervisão do estágio pode ser prejudicada pelo elevado número de atribuições do enfermeiro e pelo baixo número de professores supervisores que auxiliam a condução do ECS. Baseado na importância da realização de um estágio de qualidade, propõe-se responder aos seguintes questionamentos: qual a visão dos enfermeiros preceptores acerca do estágio curricular supervisionado? Quais as dificuldades enfrentadas por eles durante a supervisão dos acadêmicos? Este estudo visa coletar informações que contribuam para que os enfermeiros e acadêmicos tenham maior aproveitamento $\mathrm{e}$ aprendizado durante o ECS, objetivando identificar a opinião dos enfermeiros supervisores do estágio hospitalar acerca dos fatores que podem dificultar sua atuação durante a supervisão; identificar 
qual a importância do estágio supervisionado para os enfermeiros e verificar a percepção dos enfermeiros quanto à sua participação durante a disciplina de estágio curricular supervisionado hospitalar. Contribuições nesse campo são de significativa importância visto que o estágio é fundamental na formação dos acadêmicos que em breve irão atuar como enfermeiros.

\section{Método}

Este é um estudo exploratório descritivo com abordagem qualitativa, realizado no Hospital de Clínicas (HC) de uma cidade no interior de Minas Gerais nos setores que são campo de ECS, tendo como sujeitos todos os enfermeiros que trabalham em campo de estágio nos períodos matutino ou vespertino, que atuaram como supervisores de estágio, visando a conhecer a opinião desses profissionais sobre sua atuação como supervisor do ECS.

A coleta de dados foi realizada por uma entrevistadora no período de março a abril de 2015. Dos 64 enfermeiros que trabalhavam em campo de estágio no período diurno, 57 foram convidados a participar da pesquisa, 45 aceitaram participar, 11 recusaram, 1 foi excluído por nunca ter supervisionado estágio, 7 não foram abordados por estarem de férias ou licença. Os sujeitos foram abordados em seus setores durante o turno trabalho e convidados a participar da pesquisa, sendo explicado seus objetivos assim como os riscos e benefícios. Após leitura e assinatura do Termo de consentimento livre e esclarecido as entrevistas foram realizadas em dias e horários de escolha dos participantes na própria instituição. Foi utilizado um questionário norteador composto por duas partes; a primeira formada por dados referentes à identificação dos entrevistados tais como idade, situação conjugal, escolaridade e tempo de trabalho na instituição. $\mathrm{Na}$ segunda, constam seis questões pertinentes à temática, sendo elas: 1-Qual a sua visão sobre o estágio supervisionado?; 2- Quais as dificuldades que você como enfermeiro (a) tem em supervisionar o estágio?; 3Você considera o conteúdo que você teve na graduação suficiente para torná-lo (a) apto (a) para exercer a profissão, incluindo o papel de supervisor de estágio? Por quê?; 4- Analisando a sua rotina de trabalho, me conte se você considera a supervisão de estágio uma atribuição do enfermeiro e o que o leva a pensar assim; 5- Você acha que a estrutura do estágio tem que ser mudada?; 6- Descreva para mim o que você considera que seja atribuição do enfermeiro de um hospital universitário.

As entrevistas foram áudiogravadas em locais que salvaguardaram a privacidade e o anonimato das informações 
dos atores. Em seguida, foram transcritas na íntegra, suprimindo qualquer informação que pudesse identificar o entrevistado. Os dados foram submetidos à análise seguindo os passos da análise de conteúdo proposta por Bardin, iniciando pela análise prévia, caracterizada pela transcrição e leitura repetitiva das entrevistas, visando consolidar as ideias centrais das falas. Em seguida realizou-se a exploração do material, identificando e agrupando as falas em categorias. Por fim os dados foram tratados por meio de sua inferência e interpretação, assumindo significados, valores e representações. ${ }^{7}$

A coleta de dados foi realizada após a avaliação e aprovação do projeto de pesquisa pelo Comitê de Ética em Pesquisa (CEP), parecer $\mathrm{n}^{\circ} 626.612$, e assinatura do termo de consentimento livre e esclarecido pelos entrevistados e entrevistador. Os sujeitos da pesquisa foram informados sobre seu direito de desistência a qualquer momento e que sua identidade seria preservada. Para manter o anonimato seus nomes foram substituídos por siglas.

\section{Resultados}

Foram entrevistados 45 enfermeiros do HC que trabalham no campo de ECS. Quanto ao perfil dos entrevistados, a média de idade encontrada foi de 31,9 anos; $23(51,1 \%)$ são solteiros; 22 (48,9\%) concluíram sua graduação entre 6 a10 anos; 27 (60\%) trabalham na instituição entre 6 meses a 1 ano; 18 (40\%) possuem uma especialização; 8 (17,8\%) mestrado e $3(6,7 \%)$ residência.

Após a transcrição e análise das entrevistas emergiram das falas dos enfermeiros sete categorias que abordam aspectos positivos e negativos presentes no estágio envolvendo acadêmicos, supervisores, professores, campo de estágio e a disciplina, sendo estas intituladas: preparo profissional; importância do estágio curricular supervisionado; dificuldades presentes do estágio curricular supervisionado; despreparo dos acadêmicos; atribuições do enfermeiro; sugestões de melhoria para o estágio curricular supervisionado e responsabilidade de supervisionar.

\section{Categoria 1: Preparo profissional}

Esta categoria contempla as falas dos profissionais que se referem ao estágio como uma oportunidade de construção do conhecimento teórico associado á prática, capacitando os acadêmicos para assumir o papel de enfermeiro no mercado de trabalho.

O estágio curricular supervisionado é a época em que você molda o tipo de profissional que você vai ser, é o momento em que o acadêmico vem para campo para colocar em prática e ver também um pouco da prática e da teoria que ele aprendeu na faculdade. (E24) 
É o momento em que ele vai estar conhecendo um pouco do hospital, da estrutura, dos problemas mesmo que existem e vai ser uma oportunidade dele se adaptar mais a realidade dele quando posteriormente ele estiver formado e ele assumir e isso como profissional. (E26)

O estágio é válido porque você consegue fazer uma ponte entre a teoria e a prática. (E33)

É uma parte da graduação que você vai mudar muitos conceitos e reafirmar aquilo que você veio para fazer mesmo, é onde você vai entrar mais em contato com a realidade. (E38)

\section{Categoria 2: Importância do estágio curricular supervisionado}

Esta categoria expressa a importância do estágio supervisionado no que concerne à troca de informações para o aprimoramento recíproco de acadêmicos e profissionais.

[ o estágio supervisionado] é necessário tanto para o aluno e é muito importante para o setor também, porque o aluno traz da faculdade muitas informações novas que a gente não tem, porque já tem muito tempo de formado. (E9)

Ele [estágio supervisionado] é importante em vários aspectos: para o aluno, para nós e para a comunidade. (E11)

Muito proveitoso, interessante tanto para o acadêmico quanto para a gente mesmo, porque o acadêmico que está aqui traz muita coisa nova, muita coisa que mudou, porque a enfermagem muda o tempo todo né, eu acho interessante, muito bom para os dois lados. (E17)

Eu acho ele totalmente importante e válido quando você recebe o aluno do estágio supervisionado te obriga a uma leitura maior a certos questionamentos, que as vezes você está no setor e não tem mais. (E33)

\section{Categoria 3: Dificuldades presentes no estágio curricular supervisionado}

Esta categoria descreve as dificuldades enfrentadas pelos enfermeiros durante a supervisão do ECS, conforme descrito nas seguintes falas.

Aqui a gente não pode parar o trabalho, então eles que tem que acompanhar o nosso ritmo ... falta um pouquinho de tempo para acompanhar o aluno. (E1)

Primeiramente a gente não recebe uma normativa do que é para ser avaliado no aluno, então isso dificulta muito. Em um momento que a gente poderia ter avaliado com maior segurança, de uma forma bem mais específica, a gente acaba perdendo isso com o passar do tempo (E3)

Às vezes eu percebo uma certa timidez por parte do acadêmico. Talvez um pouco de falta de interesse também e de até mesmo de curiosidade. Não é todos ne, tem exceções, mas eu percebo essa dificuldade neles. (E12)

Eu sinto muito a falta do professor conosco, mas como eu sei que o número deles é bem pequeno, limitado, então eles não podem estar em todas as unidades, em todos os momentos $e$ principalmente na hora em que o aluno precisa dele. (E18)

\section{Categoria 4: Despreparo dos acadêmicos}

Esta categoria compreende as falas dos enfermeiros no que tange ao despreparo e imaturidades dos acadêmicos para a construção de um perfil profissional durante o estágio.

Às vezes eu acho que é um pouco falho porque os alunos chegam muito despreparados, eles chegam sem saber a teoria. (E39) 
Está faltando comprometimento por parte dos alunos. (E3)

Na minha concepção, a maior dificuldade é essa, aluno despreparado e aluno desinteressado. Não sei porque esse aluno chega até aqui, né, mas eu entendo tudo que envolve a continuidade desse aluno na graduação. (E8)

Tem aluno que não demonstra muito interesse, não demonstra vontade, as vezes nem sabe se gosta da profissão ou acaba descobrindo na prática que não é aquilo que ele quer e as vezes a gente encontra dificuldade em dialogar com ele $e$ fazer ele perceber a importância do estágio. (E38)

\section{Categoria 5: Atribuições do enfermeiro}

Esta categoria descreve as atividades desempenhadas pelos enfermeiros no período de desenvolvimento do estágio curricular supervisionado, consideradas por eles atribuições de um enfermeiro de um hospital universitário.

As atividades de maior complexidade, algumas punções mais complexas, todas as questões gerenciais e administrativas e atividades relacionadas ao ensino, a educação permanente, treinamento para equipamentos. (E3)

A questão assistencial, técnicas que são privativas do enfermeiro, cuidados ao paciente grave, confecção de escala, liderança de equipe, educação continuada, educação permanente. (E7)

À função assistencial, gestão de serviços, administração de serviços que fica a cargo $e$ responsabilidade, exclusivamente nossa. (E8)

É muito amplo. Tem a parte de gerenciamento, a parte prática, gerenciar uma equipe, coordenar as atividades que são desenvolvidas dentro da unidade. (E10)

\section{Categoria 6: Sugestões de melhoria para o estágio curricular supervisionado}

Esta categoria é composta pelas falas dos profissionais enfermeiros que expressam suas opiniões e sugestões de melhorias para o estágio curricular supervisionado hospitalar após sua atuação como supervisor.

A gente poderia ter mais informações sobre o plano de ensino, seria bastante interessante.

\section{(E5)}

Eu acho que o que pode acontecer é uma maior interação do professor com o enfermeiro que supervisiona. (E15)

Eu gosto da estrutura que existe, mas eu acho que existem coisas que podem ser melhoradas. Eu gosto muito do aluno presente na unidade, a flexibilidade de horário para o aluno seria de ganho. (E18)

Se além da presença do enfermeiro do setor para supervisionar esse aluno, se ficasse o supervisor [docente] mais presente, isso ajudaria... se o supervisor da escola tivesse presente as vezes cobriria esse viés que fica. (E24)

\section{Categoria 7: Responsabilidade de supervisionar}

Esta categoria contempla as falas dos enfermeiros quanto à responsabilidade desse profissional em supervisionar o estágio curricular.

Quando você vem para um hospital universitário, você já tem que ter na cabeça que você vai se relacionar com alunos da faculdade. 
Eu entendo que a minha responsabilidade é também de acompanhar os alunos...é minha obrigação facilitar o conhecimento, não só na supervisão de estágio...eu acho que no hospital universitário a gente tem funções de docência mesmo eu sendo uma enfermeira assistencial... (E23)

Cabe ao enfermeiro ajudar, auxiliar, ser uma peça chave nesse processo ensino aprendizagem, porque conhecimento é para ser repassado e quanto mais você está conseguindo transmitir isso mais você vai estar conseguindo ajudar esse aluno, esse acadêmico e futuramente ele será um profissional que terá uma desenvoltura melhor. (E26)

Eu não acho certo eu ser responsável pelo estagiário, pelo aprendizado desse estagiário, então teria que ter um professor da faculdade o tempo todo com esse aluno. (E41)

\section{Discussão}

As falas dos enfermeiros deste estudo apontam o estágio supervisionado como uma importante oportunidade de vivenciar a prática, confrontando a teoria aprendida ao longo da graduação com a realidade dos serviços de saúde, possibilitando dessa forma, o aprimoramento do acadêmico e o desenvolvimento de um raciocínio crítico para atuar de forma mais efetiva no mercado de trabalho. Esta importância também foi evidenciada em um estudo reflexivo realizado em 2015 por pesquisadores do Mato Grosso do Sul, que destacou como benefícios da disciplina o aprimoramento de habilidades e competências do acadêmico necessárias para a atuação na enfermagem, além de promover o amadurecimento do acadêmico por meio da associação da teoria com as experiências vivenciadas na disciplina. ${ }^{8}$

Segundo a fala dos enfermeiros entrevistados, o acadêmico proporciona a renovação dos conhecimentos da equipe de saúde por ter acesso durante a graduação a informações atualizadas dos temas que envolvem a enfermagem, repassando esse conteúdo aos profissionais à sua volta durante o estágio ao mesmo tempo em que aprende com os conhecimentos e experiências dos funcionários da unidade em que está inserido. A troca de informações entre acadêmicos e equipe de enfermagem também foi relatada em um artigo de reflexão acerca do estágio curricular supervisionado realizado em 2012 por pesquisadores do Espirito Santo, ressaltando que essa disciplina fornece à unidade de saúde conteúdo atualizado estimulando a aplicação de novos conhecimentos. Nesse sentido, o acadêmico de enfermagem promove a transformação simultânea no contexto da unidade e nele mesmo. ${ }^{5}$

$$
\text { É desafiador colaborar com uma }
$$
disciplina fundamentada na participação ativa e junção de objetivos de grupos distintos. Após a experiência de supervisionar o estágio e conhecer de perto 
a realidade da disciplina, os enfermeiros entrevistados relataram as dificuldades enfrentadas enquanto supervisores. A inibição de alguns acadêmicos, a grande quantidade de tarefas a serem executadas pelo enfermeiro, a falta de acesso à documentação que rege a disciplina e o baixo número de professores supervisores foram as principais dificuldades vivenciadas no ECS. Uma pesquisa descritiva qualitativa realizada em Vassouras em 2011, com dez professores do curso de enfermagem e dez enfermeiros que supervisionam estágio na atenção básica concluiu que por envolver um contexto que vai além da sala de aula e da relação acadêmico-professor, o ECS exige uma articulação coesa e precisa entre professores, acadêmicos e enfermeiros para que a disciplina atinja seus objetivos, sendo necessário um planejamento de estágio que atenda às necessidades do serviço e da academia. ${ }^{9}$

Entrevistas realizadas em 2011, com nove enfermeiros de um hospital, apontaram que presença de aspectos positivos e negativos de forma concorrente e intensa promovem uma mescla de sentimentos nos enfermeiros supervisores referentes às suas participações no estágio. Eles sentem satisfação por possuírem a oportunidade de perpetuar o conhecimento que adquiriram contribuindo com a formação e crescimento dos acadêmicos sob sua supervisão, simultaneamente ao sentimento de frustração relacionado à dificuldade de fornecer melhor assistência ao estagiário devido à falta de recursos humanos e materiais. ${ }^{10}$

A falha na interação entre os enfermeiros e os docentes é uma das grandes barreiras a serem superadas, pois esta é fundamental para o desenvolvimento de um estágio de qualidade; visto que o acompanhamento do docente junto ao acadêmico durante a inserção deste na unidade transmite maior segurança para o estagiário e para a equipe. ${ }^{11}$ A pouca interação entre professores e enfermeiros supervisores também foi relatada em uma pesquisa realizada em 2012 com 20 enfermeiros supervisores de estágio de três hospitais do Ceará. Segundo este estudo, esta falha de comunicação está relacionada ao baixo quantitativo de professores, podendo ser sanada com um aumento no número de recursos humanos da academia. $^{2}$

A falta de interesse e o despreparo teórico do acadêmico para realizar o estágio também são dificuldades relatadas pelos enfermeiros e comprometem a realização da disciplina, visto que a forma em que o estágio irá se desenvolver está diretamente relacionada à conduta do aluno. A postura de desinteresse em aprender induz o enfermeiro a não investir na troca de informações com o acadêmico 
e a falta de conhecimento teórico dificulta a prática, pois esta é fundamental para a realização da assistência em todos os seus aspectos. $^{10,12}$

Os enfermeiros citaram com maior frequência como suas atribuições, as atividades voltadas à assistência e à gestão da unidade em que estão lotados, enfatizando pouco sua atuação frente ás questões de ensino. Por se tratar de um hospital universitário, os profissionais devem estar dispostos e preparados a colaborar com o processo de ensinoaprendizagem de diversos cursos, tanto quanto para a prática assistencial e gerencial, devendo ser informados sobre a importância de sua atuação no ensino ao serem admitidos na instituição. Um estudo realizado em 2009 com oito enfermeiras de um hospital público do sul do Brasil, que concluiu que o desconhecimento acerca da função de um hospital universitário por parte dos funcionários da instituição também pode dificultar a troca de conhecimento entre acadêmicos do ECS e a equipe de saúde. ${ }^{13}$

Devido ás várias responsabilidades que possuem, muitos enfermeiros sentem que a supervisão torna sua rotina ainda mais pesada, acreditando ser esta, uma atividade que deveria ser assumida por um docente. A Lei Federal 11788 de 25 de setembro de 2008 em conjunto com a Resolução COFEn n441/2013, esclarecem essa questão ao afirmar que durante o estágio, profissionais e docentes devem atuar em equipe, visto que as instituições de saúde públicas ou privadas podem oferecer estágio somente mediante a indicação de um profisssional na área de conhecimento do estágio em questão, para orientar e supervisionar até 10 alunos ao mesmo tempo, sendo facultativo a esse funcionário o aceite do cargo e somente permitido a realização da função em conjunto com um docente supervisor. ${ }^{3,14}$

Durante as entrevistas, os enfermeiros sugeriram um aumento na carga horária cursada pelo acadêmico no ECS, pois acreditam que esse acréscimo proporcionaria um ganho para a experiência e aprendizagem do acadêmico. No entanto, o estágio supervisionado de enfermagem da instituição é regulamentado pela Resolução $\mathrm{N}^{\circ} 001$ de 21 de maio de 2003, que estabelece a obrigatoriedade do estágio e sua carga horária dividida entre atuação em saúde pública e atuação hospitalar, sendo exigido o cumprimento total de 480 horas-aula, destas, 30 horas semanais e 6 horas diárias. $^{15}$

Observou-se ainda através da opinião dos entrevistados a importância de terem acesso ao plano de ensino da disciplina, fato que auxiliaria a aceitarem com menor resistência a tarefa de coordenar e supervisionar as atividades 
realizadas pelos alunos em estágio sob suas responsabilidades conforme a Resolução COFEn n ${ }^{\circ} 441 / 2013 .^{14}$

\section{Considerações finais}

Conclui-se por meio dos resultados obtidos que as hipóteses levantadas pelos pesquisadores são verdadeiras, sendo a supervisão do estágio diretamente influenciada pela grande quantidade de atribuições do enfermeiro assim como pelo baixo quantitativo de professores supervisores em acompanhamento do ECS.

A falta de tempo dos enfermeiros devido ao elevado número de atividades exercidas no turno de trabalho foi um fator limitador do estudo, pois impossibilitou que alguns sujeitos participassem da pesquisa.

Uma minoria dos sujeitos entrevistados acredita não ser sua atribuição acompanhar os estagiários demonstrando desconhecimento da resolução do COFEn que descreve o papel do enfermeiro como supervisor.

As categorias emergentes dos discursos dos sujeitos nos permitiram avaliar suas opiniões sobre suas atuações no estágio supervisionado, verificando que grande parcela dos entrevistados diz se sentir no dever de colaborar com o processo de ensino dos acadêmicos por trabalhar em um hospital universitário.

A importância do estágio para os enfermeiros também foi levantada, apresentando como fatores positivos a troca de informação entre acadêmicos e profissionais promovendo a atualização dos mesmos, assim como a promoção do estímulo à busca de conhecimento para exercer a função de supervisão atendendo as dúvidas dos acadêmicos. Ademais, o ECS permite a vivência de experiências únicas de associação de teoria e prática que serão determinantes para a formação, qualificação e elaboração do perfil do futuro enfermeiro.

Por se tratar de uma disciplina que exige a interação das instituições de saúde e ensino, o ECS sofre influência direta de ambas as partes, negativa e positivamente.

As principais dificuldades presentes no estágio, segundo os relatos dos enfermeiros entrevistados, foram $\mathrm{O}$ despreparo de alguns acadêmicos que apresentam pouco embasamento teórico ou desinteresse em realizar as atividades propostas, assim como a falta de acesso ao plano de ensino e o baixo número de professores supervisores, que dificultam o acompanhamento dos acadêmicos com maior frequência.

As facilidades emergentes da relação entre academia e instituição de saúde relatadas pelos entrevistados foram o interesse e disposição dos enfermeiros em supervisionar os acadêmicos e a segurança desses profissionais em passar informações 
durante sua atuação no ECS.

O estágio é primordial para a formação acadêmica, auxilia no crescimento dos profissionais que participam da supervisão e poderá ser ainda mais eficiente com o estreitamento dos laços entre a academia e o serviço de saúde disponibilizado como campo de estágio.

Este estudo nos permite inferir sobre a necessidade de realizar novas pesquisas acerca da temática em questão com a finalidade de abordar perspectivas diferentes, levantar problemas e soluções que contribuam para traçar medidas que promovam o aprimoramento do estágio, beneficiando acadêmicos, enfermeiros, graduação e a população que recebe cuidados desses profissionais.

\section{Fomento}

Esta pesquisa não possui nenhuma fonte de fomento.

\section{Agradecimentos}

A todos os enfermeiros que disponibilizaram um pouco de seu tempo para participar da pesquisa em nome da melhoria do ensino superior, o nosso muito obrigada.

\section{REFERÊNCIAS}

1. Ministério da Educação (BR). Conselho Nacional de Educação. Câmara de Educação Superior. Resolução CNE/CES n. 3, de 7 de novembro de 2001 (BR). Institui Diretrizes Curriculares Nacionais do curso de graduação em Enfermagem. Diário Oficial da União. Brasília (DF), 9 de nov 2001, Seção 1: 37

2. Rodrigues AMM, Freitas CHA, Guerreiro MGS, Jorge MSB. Preceptorship in the perspective of comprehensive care: conversations with nurses. Rev gaúcha enferm. 2014; 35 (2): 106-12. doi: http://dx.doi.org/10.1590/19831447.2014.02.43946

Lei 11788 , de 25 de setembro de 2008 (BR). Dispõe sobre o estágio de estudantes. Diário Oficial da União, Brasília (DF). 25 setembro 2008.

3. Universidade Federal do Triângulo Mineiro (MG). Projeto pedagógico. Curso de Graduação em Enfermagem. Uberaba (MG): Universidade Federal do Triângulo Mineiro; 2009.

4. Benito GAV, Tristão KM, Paula ACSF, Santos MAS, Ataide LJ, Lima RCD. Desenvolvimento de competências gerais durante o estágio supervisionado. Rev bras enferm. 2012; 65(1): 172-78. doi: http://dx.doi.org/10.1590/S003471672012000100025

5. Lima TC, Paixão FRC, Cândido EC, Campos CJG, Ceolim MF. Estágio curricular supervisionado: análise da experiência discente Rev bras enfern. 2014; 67(1): 133-40. doi: http://dx.doi.org/10.5935/00347167.20140018

6. Bardin, L. Análise de conteúdo. Edição 70. São Paulo: Revista e Ampliada; 2011.

7. Conceição VM, Dutra CDT, Pires CAA, Silva IV, Duartes JLS. Experiências de acadêmicos após estágio em um serviço na atenção primária à saúde. Revista de Enfermagem e Atenção à Saúde. 2012 [acesso em: 20 mai 2016] 1(1): Disponível em:

http://www.uftm.edu.br/revistaeletronica/in dex.php/enfer/article/view/290/282 
8. Umann J, Guido LA, Silva RM. Estresse, coping e presenteísmo em enfermeiros que assistem pacientes críticos e potencialmente críticos. Rev Esc Enferm USP. 2014; 48(5):891-98. doi:10.1590/S0080-623420140000500016

9. Rodrigues LMS, Tavares CMM. Estágio supervisionado de enfermagem na atenção básica: o planejamento dialógico como dispositivo do processo ensinoaprendizagem. Rev RENE. 2012 [acesso em: 20 mai 2016]; 13(5):1075-83.

Disponível em: http://www.revistarene.ufc.br/revista/index .php/revista/article/viewFile/62/pdf

10. Tavares PEN, Santos SAM, Comassetto I, Santos RM, Santana VVRS. A experiência de enfermeiras assistenciais com estudantes de enfermagem: uma análise fenomenológica. Rev RENE. 2011; 12 (4): 798-807. doi: http://dx.doi.org/10.1590/S008062342009000300005

11. Garcia SD, Vannuchi MTO, CiciliatoCZ, Ignotti BS. Academia e serviços de saúde na consolidação do internato de enfermagem. Semina cienc biol saúde. 2015 [acesso em: 20 mai 2016]; 36 (1): 123-36. Disponível em: http://www.uel.br/revistas/uel/index.php/se minabio/article/view/19152/16966

12. Barlem JGT, Lunardi VL, Barlem ELD, Bordignon SS, Zacarias CC, Filho WDL. Fragilidades, fortalezas e desafios na formação do enfermeiro. Esc Anna Nery. 2012; 16 (2):347-53. doi: http://dx.doi.org/10.1590/S141481452012000200020

13. Sales PRS, Marin MJS, Filho CRS. Integração academia-serviço na formação de enfermeiros em um hospital de ensino. Trab. Educ. Saúde. 2015; 13 (3): 675-93. doi: http://dx.doi.org/10.1590/1981-7746sip00057

14. Resolução Cofen $n^{\circ}$. 441, de 15 de maio de 2013 (BR). Dispõe sobre participação do Enfermeiro na supervisão de atividade prática e estágio supervisionado de estudantes dos diferentes níveis da formação profissional de Enfermagem. Diário Oficial da União, Brasília (DF). 15 Maio 2013.

RECEBIDO: $14 / 06 / 2016$

APROVADO: $15 / 06 / 2017$

PUBLICADO: $31 / 07 / 2017$ 